\title{
Design de Serviço no Setor Hoteleiro: Experiência do Colaborador em um Resort
}

\author{
Service Design in Hospitality Sector: Employee Experience in a Resort
}

BORGES, Barbara; Titulação; Universidade Positivo

barbaracborges@gmail.com

HOBI, Guilherme; Titulação; Universidade Positivo

guilherme.hobi@gmail.com

USSYK, Paula; Titulação; Universidade Positivo

paula.ussky@gmail.com

\begin{abstract}
Resumo
Com o design de serviço como principal motivador, foi desenvolvido um projeto a respeito da resolução de problemas complexos no ramo hoteleiro. Trazendo o ponto de vista da experiência do colaborador e tendo como metodologia foi aplicada o design thinking (BROWN, 2009). Utilizando a fase de imersão para o diagnóstico inicial, a ideação para resolução do problema, e o refinamento e prototipação para as soluções resultantes do trabalho colaborativo dos participantes. Foi constatado nesses resultados, a importância da experiência do colaborador e como a aplicação do design de serviços nesse contexto já trouxe resultados muito positivos, tanto para o problema de comunicação interna dentro do resort, quanto para o trabalho em equipe.
\end{abstract}

Palavras Chave: hotelaria; design de serviço; experiência do colaborador.

\begin{abstract}
With service design as the main driver, this project was developed considering wicked problems resolutions in the hospitality sector. Approaching from an employee experience point of view and using design thinking (BROWN, 2009) as a methodology. For the initial diagnosis, an immersion phase was utilized, followed by ideation for solving the problem. Ending with refinement and prototyping of the solutions presented on the collaborative work with the participants. Through the results, it has been shown the importance of the employee experience and how applying service design in this context can bring many positive outcomes, not only regarding the internal communication problem inside the resort, but also teamwork as a whole.
\end{abstract}

Keywords: hospitality; service design; employee experience. 


\section{Introdução}

O objetivo do projeto foi explorar problemas de serviço em um resort considerado de referência no país, para melhorar a experiência dos colaboradores, visto que estes possuem grande impacto em como os hóspedes vivenciam o resort.

Aplicando os conhecimentos de design de serviço, o projeto se iniciou com a fase de pesquisas, que consistiu em conduzir entrevistas e coletar observações como cliente oculto ${ }^{1}$. Nesse contexto, as estruturas organizacional, física e pessoal do hotel foram analisadas. A partir desse ponto os principais problemas de backstage foram explorados, destacando a relação entre colaboradores $^{2}$ e como isso refletia na experiência do hóspede.

Kozak (2016) nota a importância de trazer a perspectiva do design de serviço para a indústria hoteleira, e como a implementação da filosofia do design thinking, faz uma grande diferença para as empresas que adotam-na.

Este artigo aborda a forma como os autores buscaram trazer soluções para problemas enfrentados pelos colaboradores "por trás das cortinas", utilizando ferramentas de design por meio de workshops, e também reforçando o conceito de cocriação com a participação de um grupo de colaboradores no desenvolvimento desses resultados. O desfecho do projeto, mostra como a aplicação desse conhecimento, traz resultados positivos para todos os envolvidos no serviço.

\section{Contexto}

\subsection{Hotelaria}

A indústria hoteleira, é um dos campos que mais cresce no país: uma área que tem como finalidade atuar nas áreas de hospedagem, alimentação, segurança, entretenimento e outras atividades relacionadas com o bem-estar dos hóspedes, além disso a hotelaria também possui seu cunho administrativo e empreendedor. Fazendo parte tanto do turismo de lazer, quanto de negócios. (GUIA DO ESTUDANTE, 2012)

Com um crescimento cada vez maior de setores de serviço no país, como educação, saúde e lazer, percebe-se um grande destaque no contexto de hotelaria. (BRANCO; RIBEIRO; TINOCO, 2010). Quando se volta o olhar para esse setor, é possível perceber a importância de um serviço de qualidade e atendimento voltado para o cliente. De acordo com Júnior (2014) "Nos últimos 90 anos, a sociedade testemunhou uma importante evolução econômica, migrando de uma realidade predominantemente baseada em manufatura para uma baseada em serviços", e isso tem afetado muito os modelos de negócio atuais, principalmente no que diz respeito a lazer e entretenimento, uma vez que são áreas onde a experiência do usuário é levada a um nível maior de importância.

Seguindo essa linha, considera-se que o consumo e prestação de serviços estão diretamente ligados à experiência que os acompanham. É importante destacar também que o consumidor exige cada vez mais uma qualidade não só dos produtos tangíveis que utilizam, mas também das

\footnotetext{
${ }^{1}$ Ferramenta utilizada para medir a qualidade do atendimento em um serviço ou buscar informações sobre ele de forma anônima, se fazendo passar por um cliente comum.

2 o termo colaborador serve geralmente para aqueles que colaboram com uma organização por meio da oferta de trabalho. Sendo assim, é um termo equivalente a trabalhador ou funcionário, podendo incluir tanto aqueles que fazem parte do quadro de trabalhadores quanto os prestadores de serviço. (NUNES, 2015)
} 
experiências e produtos intangíveis atrelados. Norman (1988) diz que o novo papel das empresas é organizar a criação de valor, na perspectiva de considerar os clientes não como o fim do processo de produção, mas como coprodutores de valor.

O caso estudado nesse projeto está inserido no contexto da hotelaria, e se destaca como resort de referência no país de acordo com as plataformas de avaliação TripAdvisor e Guia 4 Rodas. Tendo em vista a oportunidade de melhorar ainda mais os seus serviços e investir em novos métodos de inovação estratégica, o resort concordou em desenvolver um projeto de design de serviço que explorasse e cocriasse uma solução, oferecendo um resultado com alto potencial de ser implementado na empresa. O projeto, mesmo atendendo um cliente real e trazendo soluções válidas, apresenta cunho acadêmico. Por questões de confidencialidade, a empresa em questão solicitou discrição de informações como dados coletados que fazem referencia à questões internas, por essa razão alguns elementos apresentados são apenas ilustrativos.

É importante destacar que dentro do resort em questão, a estrutura organizacional é subdividida em células, e possui três níveis hierárquicos: diretores ou gerentes, coordenadores e operadores (LIMA JÚNIOR, 2014). "A filosofia organizacional de células, com coordenações específicas e autonomia de planejamento, permite uma atuação do sistema de serviço integrado e cooperativo, permitindo fluxo aberto e contínuo da informação", explica Júnior (2014). Essa estrutura contribuiu para que, no desenvolvimento do projeto, as questões apresentadas fossem trabalhadas dentro desse contexto. Entender o funcionamento das células e as relações dentro e entre cada uma, foi um passo significativo no processo.

\subsection{Design de Serviço}

A metodologia utilizada neste projeto foi a do Design de Serviço, uma abordagem centrada no usuário, que busca através de pesquisas e sessões de cocriação entender as características, necessidades e desejos dos envolvidos em um serviço, e projeta soluções baseadas nestas constatações. Seu objetivo é proporcionar serviços úteis, utilizáveis e desejáveis para os clientes e eficazes e eficientes para as organizações (MORITZ, MAGER \& COUNCIL, 2014).

O processo de Design de Serviço tem como base o Design Thinking que une o que é desejável para as pessoas, viável para o negócio e possível do ponto de vista tecnológico (BROWN, 2009). Com base na Figura 1, é possível obter um entendimento geral desta abordagem a partir do pensamento dos principais autores da área. 
Figura 1 - Mapa mental dos principais autores de design de serviço
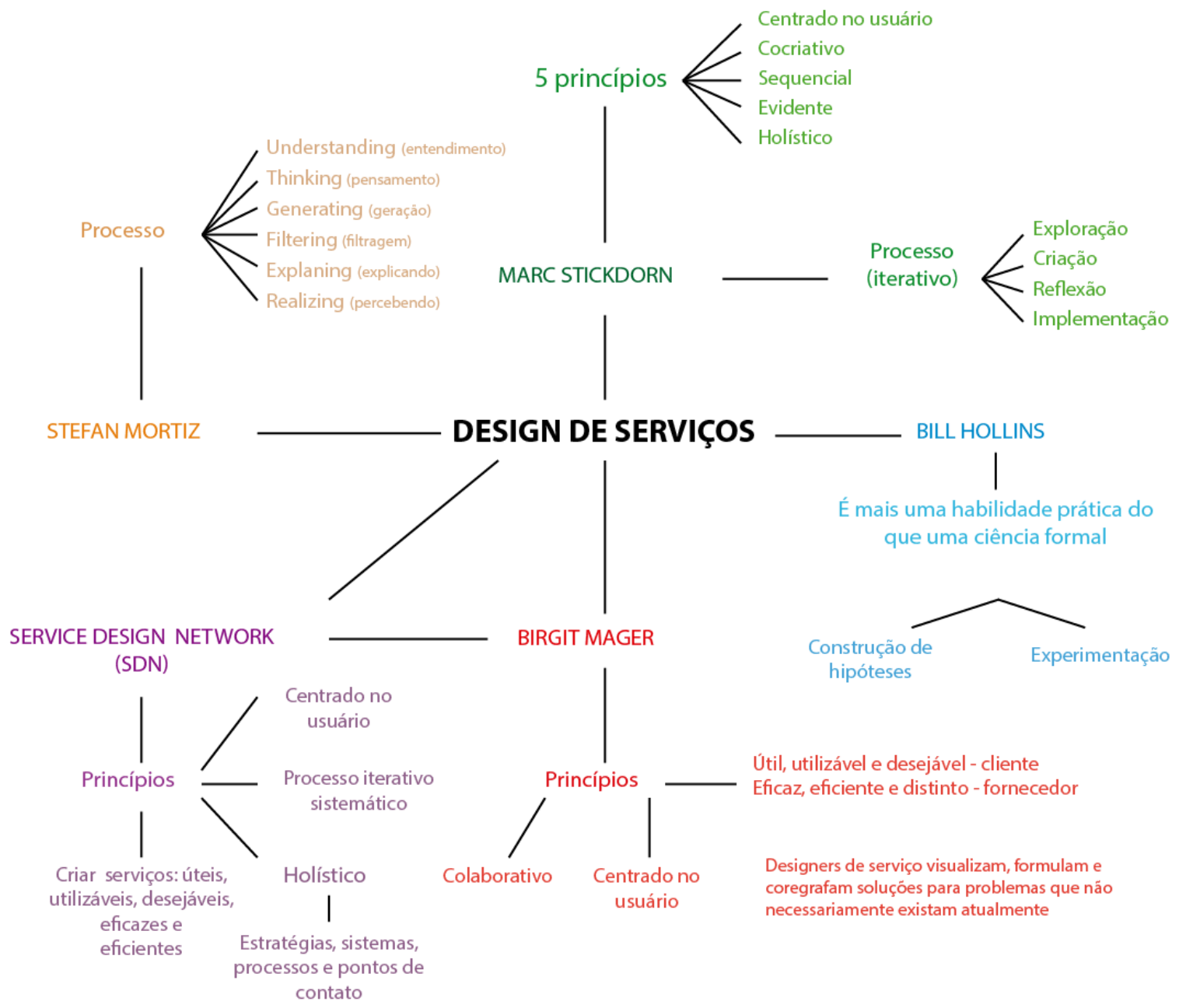

Fonte: Design de serviços no setor público: Caso estudado da lei de liberação de eventos da prefeitura de Joinville - SC, 2016, p. 1079-1090

Após análise do mapa mental, é possível afirmar que no design de serviços é imprescindível o foco no usuário durante todo o processo. Deste modo, o objetivo da abordagem é criar serviços mais competitivos, desejáveis e sem falhas, que aumentem diretamente a satisfação dos clientes além de tornar as organizações mais eficazes e eficientes (WHICHER, SWIATEK, \& CAWOOD, 2013). Tendo em vista o contexto hoteleiro, no qual diversos tipos de pessoas, setores, clientes, ambientes e serviços estão inseridos, o design de serviço como resolução de problemas se mostra uma ótima opção, considerando sua visão holística e centrada em todos os envolvidos no processo.

\subsection{Experiência do Colaborador}

Cada vez mais é possível notar a importância de pensar em serviços e produtos com o olhar voltado para o seu usuário, tendo em vista que estão cada vez mais exigentes e que são fator decisivo para fazer um negócio crescer ou morrer.

Em contrapartida, temos os colaboradores, que são a peça principal na entrega de um serviço, algo que é consumido ao mesmo tempo é produzido, é intangível, não pode ser armazenado ou de propriedade (MORITZ, 2005). A experiência do colaborador no ambiente de trabalho, vale 
tanto quanto a do usuário. Isso porque um funcionário insatisfeito, desmotivado ou sobrecarregado, dificilmente vai conseguir prestar um atendimento de excelência para os clientes.

"A essência do "ambiente de trabalho como uma experiência" é criar contextos onde as experiências física, emocional, intelectual, virtual e aspiracional são cuidadosamente projetadas e orquestradas para inspirar, engajar, desenvolver e ampliar o desempenho dos colaboradores." (Ranieri, Arthur. 2017)

Ranieri (2017), afirma a respeito da experiência do colaborador: "surge um conceito ainda pouco explorado e que com grande potencial de se tornar uma das principais alavancas para a melhoria dos níveis de engajamento e desempenho das pessoas". Deste modo, quando falamos em "experiência do usuário", na área do design de serviço, estamos considerando todos os stakeholders deste serviço, pois todos eles de alguma forma utilizam e interferem no serviço em questão.

\section{Desenvolvimento}

Com base nos estudos recentes a respeito da experiência do colaborador (RANIERI, Arthur. 2017), que tem o objetivo consequente oferecer uma melhor experiência ao usuário final, os autores deste projeto direcionaram o tema do trabalho de conclusão para a área de hotelaria, estudando o contexto de hospitalidade e lazer, relacionando isso experiência de um serviço de excelência.

Para estruturação do projeto, os autores aplicaram o processo e as ferramentas do design de serviços. Seguindo os princípios da abordagem, num período de 5 meses, o projeto foi desenvolvido com as seguintes etapas: pesquisa, definição do problema, ideação e resultado, contando com a participação dos autores, dos colaboradores e das lideranças do hotel.

\subsection{Pesquisa}

Focando em primeiramente entender o contexto, história e propósito do Resort, foi feita uma pesquisa como cliente oculto. Os autores passaram um dia no Resort como hóspedes, observando o funcionamento de toda a estrutura: funcionários, transporte, governança, atendimento, alimentação, opções de lazer e serviços, estrutura física e capacidade de resolução de problemas.

Além disso também foi realizada uma entrevista, com a coordenadora da célula de CRM (Customer Relationship Management) do hotel, a respeito dos principais problemas enfrentados tanto externa, quanto internamente. Tudo isso, trouxe dados de extrema relevância e importância para o direcionamento do projeto.

Essa pesquisa primária e os dados colhidos na entrevista tornaram possível enxergar mais claramente as áreas para onde seria possível direcionar o projeto. Algumas delas foram: Célula de Eventos, Célula de Atendimento ao cliente e Comunicação interna dos colaboradores. Este último chamou a atenção dos autores, por ser um problema com uma maior possibilidade de resolução através da metodologia a ser aplicada, apesar das outras não terem sido descartadas.

Então levando em consideração o tempo de duração do projeto e discussões com a coordenadora de CRM, decidiu-se trabalhar com todas as células, a fim de verificar a validade das questões mapeadas até então. 


\subsection{Definição do problema}

Com a direção definida, o projeto seguiu com o intuito de desvendar as áreas que seriam mais beneficiadas, utilizando soluções que o design de serviço poderia proporcionar nesse contexto.

Os dados coletados anteriormente foram indexados em um relatório e os autores fizeram o planejamento da próxima visita ao resort. Focando em descobrir os problemas de forma mais concreta, o plano foi de fazer entrevistas com líderes de 4 das principais células e realizar um workshop exploratório com os colaboradores. Essas duas tarefas foram realizadas para que o real problema (ou problemas) enfrentado pelo resort ficasse evidente.

\subsection{Entrevistas}

Foram realizadas entrevistas em profundidade com os líderes das células: de Bares e Restaurantes, de Transporte, de Governança e de CRM. Utilizando um método de pesquisa qualitativa em um modelo de diálogo, as principais questões enfrentadas pela liderança começaram a ficar mais claras. Mesmo sendo células bem diferentes, um problema em comum surgiu: a comunicação entre os colaboradores.

\subsection{Workshops}

Os autores estruturaram dois workshops como meio de desenvolvimento do projeto. As atividades foram construídas com princípios e ferramentas da área fundamentados nos livros Isto é Design Thinking de Serviços (STICKDORN, 2010) e 101 Design Methods (KUMAR, 2012).

\subsubsection{Workshop Exploratório}

Com a intuito de entender os problemas enfrentados tanto dentro das células, quanto entre elas, foi realizado um workshop exploratório com os colaboradores do resort. Com 24 participantes de 10 células diferentes, a dinâmica aconteceu no período da tarde e teve duração de 4 horas.

Os participantes foram divididos em 5 equipes, e após uma breve introdução e explicação do objetivo do projeto, foram aplicadas 6 ferramentas de design, sendo elas:

- Que bom, que tal, que pena

- Brainstorming

- Painel de causa e efeito

- $4 \times 4 \times 4$

- Mapa de impacto

- Aquário

Das ferramentas citadas, duas delas foram desenvolvidas pelos autores especificamente para o projeto em questão, sendo elas o painel de Causa e Efeito e o Mapa de Impacto. Ambas com o objetivo de analisar e aprofundar os problemas apontados por cada equipe.

Causa e Efeito: com um problema específico no centro, a equipe deveria pensar em 3 itens que causam esse problema, e 3 efeitos que ele tem no serviço. É uma forma de aprofundar o problema, e instigar os participantes a ter uma visão holística da questão. (Figura 2) 
Mapa de Impacto: pensando nos atores do serviço, a ferramenta visa entender como um problema específico impacta os dois lados: o prestador de serviço (empresa) e o consumidor (cliente). Isso coloca em perspectiva como algo pontual pode prejudicar tantas pessoas, e a importância de trazer uma solução para a questão. (Figura 3)

Figura 2 - Causa e Efeito: explorando os problemas

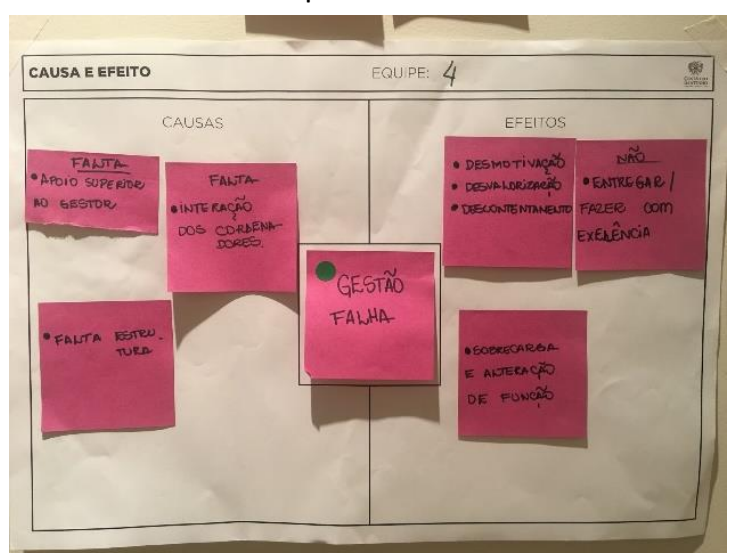

FONTE: Autores, 2017
Figura 3 - Mapa de Impacto: efeitos do problema para a empresa e para o cliente

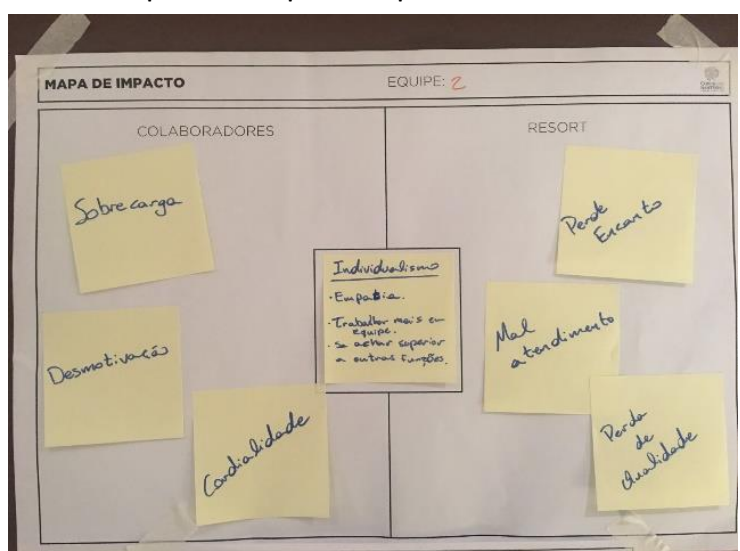

FONTE: Autores, 2017

Cada atividade foi explicada e exemplificada, e conforme os participantes progrediram no desenvolvimento, os facilitadores assumiram o papel de instigar e incentivar o uso da ferramenta em questão, tirando dúvidas e auxiliando no processo.

Após indexação dos dados colhidos no workshop, os autores classificaram os problemas em duas árvores de problemas, esses se relacionando de diversas formas. Os 135 problemas mapeados foram divididos da seguinte forma:

\section{Problemas dentro da célula:}

\section{COMUNICAÇÃO}

- Equipe

- Gestão (Treinamento e atividades; Salário; Desvalorização e desmotivação; Sobrecarga de trabalho)

- Infraestrutura (Alimentação; Uniforme; Recursos; Espaço)

\section{Problemas entre células:}

- Equipe

- Gestão

- Relacionamento 
Tendo em vista que a maior parte das questões realmente tinha uma relação com a comunicação interna e relacionamento entre colaboradores foi feita a indexação dessas informações e um novo alinhamento dos dados coletados com a Coordenadora da equipe de CRM. Desta forma, o projeto se focou no seguinte desafio: Como integrar as células para que as informações do hotel estejam alinhadas entre os colaboradores?

\subsection{Workshop co-criativo}

Com o desafio do projeto definido, o segundo workshop foi aplicado. Agora com o intuito de idear e trazer soluções para os problemas que eles mesmos tinham evidenciado, os 20 colaboradores foram distribuídos em 4 equipes, com pessoas de áreas diversificadas. 0 workshop teve duração de 6 horas e teve as seguintes ferramentas como atividade:

- Brainstorming

- World Cafe

- Refinamento

- O quê? Como? Por quê?

- Etapas do serviço

- Jornada do colaborador

- Manchete do futuro

O workshop se iniciou com um grande desafio para todos, mas ao executar as tarefas, utilizar as ferramentas, gerar e refinar as soluções, cada uma das equipes apresentou sua solução final, em forma de um serviço coerente e implementável. Com os pilares do design de serviço (Stickdorn, 2010) como guias do processo, os participantes trabalharam de forma eficiente e extremamente colaborativa. Isso fez com que, além de gerar projetos excelentes, exercessem empatia entre eles.

As ferramentas utilizadas instigaram a criação de ideias e soluções, juntamente com a sinergia e colaboração das equipes criando uma boa atmosfera. Ao longo do workshop, as ideias foram lapidadas, organizadas e detalhadas.

Após cada time ter o seu conceito para a solução definido, foi sugerida uma atividade que visa a facilitação do processo de jornada do usuário. Essa ferramenta, chamada Etapas do Serviço, desenvolvida pelos autores, ajudou a construir a estrutura do serviço e servir de plataforma para os times escreverem tudo que acontece antes, durante e depois do serviço. Cada um em um painel diferente para ajudar a organizar a informação. 
5 - Etapas do Serviço: O que acontece antes, durante e depois?

FONTE: Autores, 2017
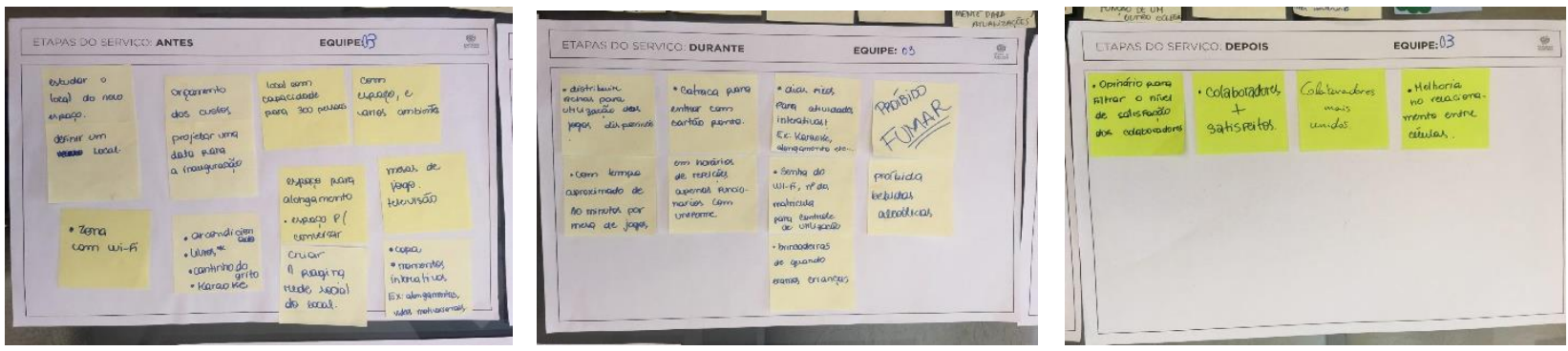

Cada equipe entregou um projeto com grande potencial para realmente resolver o problema proposto. As quatro soluções foram:

- Treinamentos integrativos entre células e hotéis parceiros

- Crosstraining entre células

- Espaço lazer e atividades de confraternização para colaboradores

- Reuniões entre células com liderança e colaboradores

\subsection{Resultado}

A Coordenadora da equipe de CRM, tomou o papel de analisar as quatro propostas e apontar qual delas seria mais adequada para ser levada a frente pelos autores, num processo de refinamento e detalhamento da solução, para entrega final.

Com o argumento de que, as outras 3 seriam mais práticas de implementar com os dados e direcionamentos já produzidos no workshop, a solução escolhida para o detalhamento foi a de criar reuniões entre as células, com a participação tanto das lideranças, quanto de colaboradores representantes. O objetivo seria trazer a visão e experiência das pessoas que lidam diretamente com o hóspede para os alinhamentos e planejamentos de estratégia do hotel. Isso não só contribuiria com dados mais ricos, mas também geraria uma maior interação dos colaboradores com outras células, aproximaria a "linha de frente" de seus coordenadores e supervisores, e daria a ele um espaço de fala, valorizando seu trabalho e motivando-o a melhorar. Tudo isso resultaria em uma melhor experiência para o colaborador, refletindo em uma melhor prestação de serviço, e por consequência, uma melhor experiência do hóspede.

Levando em conta o grande número de fatores do hotel: 25 células, 120 supervisores e mais de 1100 colaboradores fixos, foi necessário pensar em uma solução que simplificasse a logística, mas não deixasse de levar em conta a necessidade de melhorar a comunicação e valorização dos colaboradores.

Por meio de uma cocriação com os líderes do hotel e os autores chegaram à solução de realizar 3 diferentes tipos de reunião, segmentando os participantes, o detalhamento das informações e o tempo disponível. A aplicação de um formato mais ágil foi sugerida para a execução, assim como o uso ferramentas de design para previsão de problemas e ideação de soluções para possíveis cenários. Esses atributos tiveram o objetivo de trazer características mais colaborativas, criativas e dinâmicas para essas reuniões. 
Reunião Mensal: O coordenador, supervisor e um colaborador representante de cada célula participam da reunião. O objetivo é recapitular os acontecimentos e problemas do mês anterior, e com base nisso, e nos dados de eventos e hóspedes do próximo mês, elaborar o planejamento para o mês seguinte, adaptando as atividades do hotel para o público esperado.

Reunião Semanal: Os coordenadores e gerentes das células participam da reunião. Em um modelo já existente, os líderes discutem os principais problemas da semana anterior e elaboraram planos de ação estratégica para a próxima, repassando as definições realizadas aos supervisores de sua respectiva célula.

Reunião Diária: Os supervisores e colaboradores participam da reunião. O líder de cada equipe deve, diariamente, alinhar as informações, tarefas e problemas a serem resolvidos com sua célula. Mantendo uma abertura para dúvidas e sugestões provenientes dos colaboradores.

Como consolidação do resultado, foram elaborados para o cliente os seguintes entregáveis: árvore de problemas, soluções criadas no workshop de ideação, mapa do processo da solução final, ferramentas e sugestão de estrutura das reuniões.

\section{Considerações finais e resultados}

O projeto em questão, contribuiu não só para a maior exploração do design de serviço e sua aplicabilidade, desdobramentos e eficácia; mas também, para o ensino desse método para pessoas que trabalham diariamente com serviços e pessoas. Algo que trouxe soluções realizadas pelos próprios colaboradores: os resultados, a empatia, a troca de experiências, a motivação e a vontade de melhorar.

Foi possível perceber que apenas com a realização dos workshops o problema de comunicação em questão já foi minimizado, pelo menos para o grupo participante. Com atividades de caráter cocriativo e colaborativo, a troca de informações, e espaço de fala que foi dado, os colaboradores conseguiram obter uma maior compreensão de seus próprios problemas, e de seus colegas. Da mesma forma, perceberam que muitas vezes, as soluções podem ser simples, se trabalhadas em conjunto.

Quanto ao tema "experiência do colaborador", foi possível constatar que este viés deveria estar sempre presente em todos os projetos de serviço, sendo levado em conta juntamente com a experiência do consumidor, pois também fazem parte desse resultado.

Com a futura implementação das soluções geradas, que já está em andamento, espera-se ver essas práticas em ação: uma maior compreensão com o outro, e uma melhora na comunicação interna. Revertendo em um melhor atendimento e prestação de serviço para os clientes do hotel, assim como uma melhor rotina de trabalho e experiência para os colaboradores. A seguir, a coordenadora do CRM que acompanhou o projeto, cita os resultados e impactos que surgiram até o momento:

Quanto ao projeto, o assunto era totalmente novo para a maioria dos membros da diretoria e lideranças, tivemos algumas resistências e tivemos um grupo que resolveu aprofundá-lo, considero um passo importante! 
A metodologia de trabalho também foi muito marcante e os colaboradores que participaram dos workshop pediram na avaliação de cliente para usarmos em nosso cronograma de treinamento e desenvolvimento as "técnicas" aplicadas por vocês. Estamos com projeto em andamento visando melhorar a comunicação em todo o Resort: lideranças, entre células e liderados, stakeholders.

Também identificamos que a média liderança pede atenção e espera mais responsabilidades, contamos com uma equipe da linha de frente sobrecarregada e média liderança subutilizada. A formação de novos líderes está dando excelentes resultados.

O maior ganho foi a maior participação de nossas equipes nas definições da empresa: colaboradores participam das definições dentro das células, média liderança assumem a operação das células e as lideranças participam de todas as ações estratégicas da empresa: planejamento estratégico, campanha de marketing, posicionamento de mercado, etc. Estamos com resultados de reputação online e de satisfação inéditos em 2018.

Eu, que acompanhei mais de perto o trabalho de vocês, fiquei responsável pelo projeto de comunicação.

Agradeço a oportunidade e os resultados já estão visíveis. O trabalho de design nem sempre é tangível e a mudança de cultura é lenta, mas gradativa e perceptível. (Coordenadora do CRM, Anônimo, 2018) 


\section{Referências}

BROWN, T. Change by Design. Estados Unidos, 2009

BRANCO, G; RIBEIRO, J; TINOCO, M. Determinantes da satisfação e atributos da qualidade em serviços de hotelaria. Rio Grande do Sul, 2010.

<http://www.scielo.br/pdf/prod/2010nahead/AOP_200903043.pdf> Acessado em Julho de 2017.

GUIA DO ESTUDANTE. Hotelaria. 2012.

<https://guiadoestudante.abril.com.br/profissoes/hotelaria/> Acessado em Agosto de 2017.

JUNIOR, J. Proposição de um modelo de inovação em serviços a partir da perspectiva do marketing de serviços. São Paulo. 2014

<http://www.teses.usp.br/teses/disponiveis/12/12139/tde-27062014-145234/pt-br.php> Acessado em Junho de 2017.

KOZAK, M.; GÜREL, D. Service design in hotels: A conceptual review. 2016. Túrquia

<https://www.researchgate.net/publication/282233687_Service_design_in_hotels_A_conceptual _review> Acessado em Outubro de 2017.

MORITZ, S.; MAGER, B.; COUNCIL, U. D. Definição: $O$ design de serviços como abordagem interdisciplinar. In: STICKDORN, M.; SCHNEIDER, J.; ORGS. Isto é Design Thinking de Serviços / Marc Stickdorn, Jakob Schneider e coautores. Porto Alegre: Bookman, 2014. p. 33.

MORITZ, S. Service Design: practical access to an evolving field. [S.I.]: Köln International School of Design, University of Applied Sciences Cologne, 2005.

NUNES, Paulo. Colaborador. 2015. <http://knoow.net/cienceconempr/gestao/colaborador/> Acessado em junho 2018.

STICKDORN, Marc. 5 Principles of Design Thinking. In: STICKDORN, Marc.; SCHNEIDER, Jakob.This Is Service Design Thinking. Canadá, 2010.

WHICHER, A.; SWIATEK, P.; CAWOOD, G. An Overview of Service Design for the Private and Public Sectors. Cardiff, 2013. 